\title{
Identifying Fuel Poverty Using Objective and Subjective Measures
}

Catherine Waddams Price

ESRC Centre for Competition Policy, University of East Anglia \&

Karl Brazier

School of Computing Science, University of East Anglia \&

\section{Khac Pham}

ESRC Centre for Competition Policy, University of East Anglia \&

\section{Laurence Mathieu}

ESRC Centre for Competition Policy, University of East Anglia $\&$

\section{Wenjia Wang}

School of Computing Science, University of East Anglia

\section{CCP Working Paper 07-11}

\begin{abstract}
The UK Government is committed to abolishing fuel poverty amongst vulnerable households by the year 2010 and in the general population by 2016, but definition and measurement of fuel poverty remains controversial. We define a new measure of subjective household experience and explore links between this measure and the official objective definition, using a unique data set and the Family Expenditure Survey. We identify the relation between the two measures; explore the characteristics of households in each group; and how each measure is related to other household factors.
\end{abstract}

May 2007

JEL Classification Codes: L97, I38, C63

Keywords: Fuel poverty, energy expenditure 
Acknowledgements: The authors gratefully acknowledge funding from the UK Economic and Social Research Council (including grant RES-000-22-0874) for this work and from the Electricity Association for the original survey. The first author thanks Dudley Cooke and Monica Giulietti for work on the original data set. The authors of this paper are grateful for very helpful comments made by the editor and two anonymous referees, but remain responsible for any remaining errors.

\section{Contact details:}

Corresponding author: Catherine Waddams Price, ESRC Centre for Competition Policy, University of East Anglia, Norwich, NR4 7TJ

c.waddams@uea.ac.uk 


\section{Introduction}

Abolishing fuel poverty is a major focus of the UK Government's policy across several departments (DTI Energy Group, 2003). The Government defines fuel poverty as occurring when a household "needs to spend more than $10 \%$ of its income on all fuel use to heat its home to an adequate standard ${ }^{1}$ of warmth" (DTI Energy Group, 2001). The government is committed to removing all vulnerable households from fuel poverty by 2010 (a vulnerable household includes children or those who are elderly, sick or disabled), and all others by 2016 and has implemented several policies and measures since 2001 to tackle the issue. However, fuel poverty is a complex and multi-faceted problem involving a wide range of economical, personal, social and environmental issues at various levels of society. In this paper we explore the relationship between an objective measure based on the official criterion and whether or not householders believe that they can afford sufficient energy to their needs. This subjective belief will have an important impact on the acceptability of government policies to reduce both its own measure of fuel poverty and to meet environmental targets.

As a result of price rises in 2005-2008, the Fuel Poverty Advisory Group estimated that the number of fuel poor would rise to 2.5 million in 2007, twice as many as in 2004. A similar doubling to 2 million is anticipated amongst vulnerable households. Although retail energy prices fell in early 2007, the long term trend is likely to be upward, reflecting concerns about security of supply and the environment. Against this background, it is even more important to ensure that the limited resources of government and companies are appropriately targeted and that fuel poor households are correctly identified. Indeed the regulator itself has highlighted the need for accurate targeting (Ofgem, 2005).

\footnotetext{
${ }^{1}$ The DTI Energy Group (2001) definition of adequate warmth, adapted from that of the World Health Organization, is $21 \square \mathrm{C}$ for the living room and $18 \square \mathrm{C}$ for other rooms.
} 
This paper explores the characteristics of the two concepts of fuel poverty, the factors associated with them and the relationship between the government's official definition of fuel poverty (above) and the subjective belief that a household cannot afford sufficient energy for its needs. It uses information from a unique data set to link the objective measure with a subjective assessment in a way not often possible for government targets, and identifies how achieving the objective target might affect subjective experiences. In this respect it mirrors some of the literature on the economics of happiness, for example Blanchflower and Oswald, 2004, and uses quantitative analysis to address some qualitative aspects of wellbeing as in Hancock et al., 2003.

The connection between fuel and more generic poverty has been explored in a number of papers (e.g. Waddams Price and Biermann, 1998, Sefton, 2002). By definition, fuel poverty affects those with high fuel expenditure or low incomes or both, but many low income households are not fuel poor, and some fuel poor households do not have low income. Nevertheless the probability of being in fuel poverty clearly increases as income falls (Bennett et al., 2002).

The main data used in this study were the responses to a questionnaire, administered to low income consumers, which had been designed to yield information on issues associated with fuel poverty (self-disconnection and rationing). We supplement a traditional social science methodology by using data mining techniques to suggest additional factors to include in the model. Potential factors identified through the objective data exploration were further analysed and tested using more traditional statistical tools. Our results thus extend the descriptive presentation of the original data set (Cooke et al., 2001), focus on a single policy objective (reducing fuel poverty), and identify the difference between objective measures and subjective experience. 
The next section describes our methodology in more detail, and section 3 presents the results; section 4 discusses the results, including the policy implications of these findings.

\section{Methodology}

Our methodology has three novel aspects. First, we define a new subjective concept of fuel poverty, compare this to the traditional definition, and explore the determinants of a household being in fuel poverty by either definition. Second, we use a unique data set of low income households and compare its results with those of the Family Expenditure Survey. And third, we use data mining techniques to explore potential determinants of fuel poverty from our 'in house' data set. In the following sections we discuss the definitions of fuel poverty, the data set and how we built the models.

\subsection{Data and definitions}

Our main data are an extensive survey of low income consumers in the summer of 2000 , administered by interviews in the homes of 3417 consumers. While the incidence of fuel poverty has changed since then (FPAG, 2007), the official definition of the objective measure has not, and we believe that subjective experiences of feeling fuel poor are also likely to be broadly stable. If anything, more households might feel fuel poor after a period of rising prices such as that of 2005-06. Respondents to the survey were chosen to be representative of prepayment electricity consumers, a group whose income is lower than average (Cooke et al., 2001), and included matched groups of consumers paying for energy by credit. The data were collected as part of a study commissioned by the Electricity Association ${ }^{2}$ to identify the extent of self-disconnection and associated problems at a time when the benefits and costs of prepayment meters were being

\footnotetext{
${ }^{2}$ The project's steering committee represented government, regulators, consumer and other interest groups, suppliers and the research team.
} 
seriously questioned. The sample consisted of about 150 electricity prepayment consumers and 100 credit consumers in each of the 14 electricity distribution regions in England, Wales and Scotland. The credit consumers were selected to explore potential parallel problems of 'rationing', and to match the profile of prepayment households in terms of income and other characteristics. The sample is therefore not representative of the population as a whole, and the data have been analysed in an unweighted form (for example no geographic weights have been applied). Questionnaires were administered in face-to-face interviews in respondents' homes, with an incentive of $£ 15$ for each completed survey yielding a response rate close to $80 \%$. The data include information on: fuel supplier, payment method, switching energy suppliers; ${ }^{3}$ heating method, the extent to which the house was fully heated, whether the respondents felt able to heat their home adequately, and affordability of fuel bills; advice on energy efficiency sought and received; practical issues associated with using prepayment meters and charging prepayment cards; convenience of credit payment methods; estimates of expenditure; difficulties in paying for energy; whether prepayment meter installation was associated with payment arrears; experience of disconnection from prepayment meters; whether consumption would be altered by a change in the price of gas or electricity, or the household's income; and standard classification details, including the household's gross income (in bands). The questionnaire and descriptive statistics of the results are available at Cooke et al., 2001, and we refer to this data set as the low income survey. We also analysed data from the contemporary (2000-01) Family Expenditure Survey for comparison.

\footnotetext{
${ }^{3}$ The survey was undertaken a year or so after retail energy markets were fully opened
} 
Table 1: Proportion of households in each income group, by payment method, Low Income Group (numbers in parentheses)

\begin{tabular}{|l|l|l|l|}
\hline $\begin{array}{l}\text { Income bracket } \\
\text { Es per annum }\end{array}$ & $\begin{array}{l}\text { Percentage of } \\
\text { PPM electricity } \\
\text { only users } \\
(\mathbf{1 1 5 0 )}\end{array}$ & $\begin{array}{l}\text { Percentage of } \\
\text { PPM users for } \\
\text { both fuels (941) }\end{array}$ & $\begin{array}{l}\text { Whole } \\
\text { sample } \\
\mathbf{( 3 4 1 7 )}\end{array}$ \\
\hline $0-6,499$ & $27 \%$ & $30 \%$ & $24 \%$ \\
\hline $6,500-12,499$ & $23 \%$ & $28 \%$ & $23 \%$ \\
\hline $12,550-17,499$ & $12 \%$ & $13 \%$ & $11 \%$ \\
\hline $17,500-24,999$ & $10 \%$ & $7 \%$ & $10 \%$ \\
\hline $25,000-34,999$ & $6 \%$ & $5 \%$ & $7 \%$ \\
\hline $35,000-49,999$ & $2 \%$ & $2 \%$ & $3 \%$ \\
\hline 50,000 or more & $1 \%$ & $1 \%$ & $1 \%$ \\
\hline Don't know or refused & $19 \%$ & $16 \%$ & $21 \%$ \\
\hline Total & $\mathbf{1 0 0} \%$ & $\mathbf{1 0 0} \%$ & $\mathbf{1 0 0} \%$ \\
\hline
\end{tabular}

To capture the experience of a household in fuel poverty, we used the answers to two groups of questions. The first pair of questions was "In general, do you feel that you are able to heat your home adequately?" If respondents replied 'no', they were asked whether this was because it was difficult to heat or because they found it difficult to afford the fuel. Respondents who gave the latter answer were classified as 'Feeling Fuel Poor' (FFP). So were those who responded negatively to another question "Do you feel that you can afford enough fuel for all your water heating and cooking needs?" Those who are labelled FFP therefore feel unable to afford sufficient fuel for either their heating or their cooking needs or both.

Consumers provided their estimated expenditure on gas and electricity, and told us their payment method. We converted their expenditure estimates into annual equivalents (for details see appendix 1). We are unable to assess whether households needed to spend more than $10 \%$ of their income on energy, so we adopt the concept of "Expenditure Fuel Poverty" (EFP) as a working measure (Bennett et al., 2002), defined as where households do spend more than $10 \%$ of income on fuel. This is a lower bound, if all households who spend more than a tenth of their income need to do so, and so renders our estimate of fuel poverty by the $10 \%$ rule conservative, since it omits households who need to spend more 
than $10 \%$ on energy but who do not do so. We explore whether our analysis suggests that those who feel fuel poor but are not expenditure fuel poor are indeed those who need to spend more than $10 \%$ of their income on energy to meet their needs adequately, but do not do so. Since income was recorded only in bands (to increase the response rate), we needed to choose a single point in each range as the most appropriate approximation, and to measure the proportion of income spent on energy we used the mid-point of each income band for this purpose. The household was defined as being in EFP if its reported annual energy expenditure exceeded $10 \%$ of this estimated income. To explore the correlation between the subjective and objective measures we identified households who were fuel poor by both measures, by only one, and by neither, and describe the characteristics of each of these four groups.

One novelty of our approach is that we used data mining techniques to identify whether there were factors from our survey which are not usually taken into account which affected either of our definitions of fuel poverty. To do this we first identified the most relevant factors for each definition; we then found which of these were significantly different from zero, drawing up two lists, of positive and negative associations, for each measure; thirdly we identified the extent of overlap between the relevant and significant factors on each list and included the general characteristics associated with such factors, based on likely causal relationships. Further details are included in appendix 2.

\subsection{Developing models}

The DEFRA website states that the main cause of fuel poverty in the UK is a combination of poor energy efficiency in houses and low incomes. Our data do not provide direct information on insulation of homes, but the standard of energy efficiency is likely to be related to income and correlated with other household characteristics which we can observe. We used two sources to develop models to explain fuel poverty. The first was previous analysis of the Family Expenditure Survey and literature in the area to identify the variables which are likely to cause 
EFP. The second source for modeling is the outcome of the data mining exercise (Brazier et al., 2005). This is used to identify additional independent variables which seem to be related to fuel poverty measured by either definition. The variable included in the model is not usually the exact factor identified, but is chosen at an appropriate level of the decision 'tree' from knowledge of the context and other relevant literature and policy documents related to fuel poverty. We then conducted logit analyses to identify the determinants and marginal effects of EFP from both the Family Expenditure Survey and the low income survey, and FFP from the low income survey. (Since the Family Expenditure respondents were not asked about difficulty in heating their homes, it was impossible to identify whether or not they felt fuel poor. Similarly the FES does not include information on the additional independent variables identified from the data mining exercise conducted on the low income sample.)

There has been surprisingly little quantitative analysis of the causes of fuel poverty, despite the collection of considerable detailed descriptions assembled by the Fuel Poverty Advisory Group (e.g. FPAG, 2007) and the simulation modelling of Sefton (2002). We base our model on Bennett et al., 2002. They found that in 1997-98 EFP was more likely in households with lower income, on income support and in retired households. Those using standard credit payment for either gas or electricity were less likely to be in fuel poverty than those paying by direct debit, reflecting the lower consumption level of such consumers. Prepayment consumers were not more likely to be EFP than others with similar characteristics, perhaps reflecting some rationing which expenditure data cannot capture. Although standard credit and prepayment are more expensive than direct debit this does not seem to dominate in determining fuel poverty in the study by Bennett et al. From this information, the first stage in our model is therefore that the probability of being fuel poor can be represented by

$P(F P)=f($ income , payment method, receipt of income support, household structure, retirement)

(1) 
We tested this model on FES data for the year in which the low income survey was undertaken (2000-2001). We also used it as a reference model to test the questionnaire data for influences on both EFP and FFP.

From the data mining exercise we sought additional factors which were associated with our two measures of fuel poverty. We identified 23 factors which were salient and significantly different from zero which were associated with EFP, and 44 associated with FFP. Some of these were spurious, and many were subsets of higher level characteristics which were more relevant to our analysis. From these features, three additional characteristics were identified to include in our model. These were whether (if using a prepayment meter) the household had self-disconnected or used emergency credit in the previous year; whether the home had full or partial central heating (this would be likely to be correlated with energy efficiency); and whether the respondent had switched or arranged to switch supplier. We expected that use of emergency credit/disconnection would be positively related to both measures of fuel poverty if it reflected the household being close to its budget constraint. Households with central heating would be less likely to be fuel poor, since they had more effective heating mechanisms and would be more likely to have installed energy efficiency measures. Switching would be negatively associated with fuel poverty for several reasons: because incumbent suppliers could block switching for households in debt; because lower prices are obtainable by switching; and because in the early days of competition (around the time of the survey) switching rates were positively related to income (Ofgem, 2003).

Thus our model (1) was extended to

$P(F P)=g($ income, payment method, receipt of income support, household structure, retirement, self-disconnection, heating, switched)

(2) 


\section{Results}

We first report associations between the two measures of fuel poverty within the low income survey data set, and provide descriptive summaries of the households who are fuel poor by both or either definition, before reporting the results of the logit analysis for FFP and EFP and exploring the likely effect of potential bias in the data. In section 3.2 we report the results of analysing the Family Expenditure Survey data (for EFP only).

\subsection{EFP and FFP in the Low Income Survey}

Table 2 shows the numbers of households who reported themselves as feeling fuel poor, or who were spending more than $10 \%$ of their income on energy.

Table 2: Contingency table for fuel poverty

\begin{tabular}{|c|c|c|c|c|}
\hline & \multicolumn{4}{|c|}{ Proportion of income spent on energy } \\
\hline \multirow{4}{*}{$\begin{array}{l}\text { Householder } \\
\text { assessment }\end{array}$} & & $<10 \%$ & $\geq 10 \%$ & total \\
\hline & Not Feeling Fuel Poor & 1638 & 527 & 2165 \\
\hline & Feeling Fuel Poor & 231 & 182 & $413(16 \%)$ \\
\hline & Total & 1869 & $709(28 \%)$ & $\underline{2578}$ \\
\hline
\end{tabular}

$25 \%$ of the households interviewed (839), are missing from the analysis, mainly because of non-response to the income question (see table 1 and discussion at the end of section 3.3). Of the respondents whose answers we could include, $16 \%$ reported feeling fuel poor, and $28 \%$ spent more than $10 \%$ of their income on energy. The $x^{2}$ statistic (40.98) exceeds the critical value for a probability of 0.001 , showing strong correlation between the measures, despite their obvious differences. The figure of $28 \%$ for the proportion of EFP households seems reasonable for a low income sample at a time when estimates of the national percentage of households in fuel poverty ranged from 7\% (DTI Energy Group, 2005 ) to around $14 \%$ (Sefton, 2002). Only about half as many people in the low income survey felt unable to afford adequate heating as are defined as EFP. Table 3 provides more information about the characteristics of each group. 
Table 3: Characteristics of households in each group (\%with each characteristic)

\begin{tabular}{|c|c|c|c|c|}
\hline & Both (A) & EFP only (B) & FFP only (C) & Not fuel Poor (D) \\
\hline Income $<£ 6,500$ pa & 78 & 80 & 19 & 10 \\
\hline Income $<£ 12,500$ pa & 97 & 97 & 63 & 42 \\
\hline Single parents & 16 & 12 & 18 & 14 \\
\hline Single adults & 24 & 29 & 27 & 20 \\
\hline Gas prepayment & 46 & 48 & 35 & 25 \\
\hline Electric prepayment & 87 & 78 & 73 & 60 \\
\hline Private rented accommodation & 5 & 9 & 8 & 11 \\
\hline LA rented accommodation & 52 & 46 & 50 & 46 \\
\hline Receiving state pension & 6. & 2 & 7 & 2 \\
\hline Receiving disability benefits & 10 & 10 & 10 & 10 \\
\hline \multirow[t]{2}{*}{ Receiving other benefits } & 76 & 79 & 76 & 77 \\
\hline & \multicolumn{4}{|c|}{ £s per annum } \\
\hline Average fuel expenditure & 910 & 877 & 603 & 608 \\
\hline Standard deviation expenditure & 436 & 491 & 319 & 320 \\
\hline Total numbers & 182 & 527 & 231 & 1638 \\
\hline
\end{tabular}

Those who are expenditure fuel poor (columns A and B) have on average both lower income and higher fuel expenditure than those who are not EFP. In contrast, those who only feel fuel poor (column C) have similar (lower) expenditure to those who are not fuel poor by either criterion (D), higher income than the EFP households (A and B), but slightly lower than those who are not fuel poor. We see that the group which spends more than $10 \%$ of its income on energy ( $A$ and $B$ ) and the smaller group who do so and also feel fuel poor ( $A$ ) share similar characteristics, suggesting that those who feel fuel poor are a 'representative' subgroup of households who are EFP. In contrast, the characteristics of those who feel fuel poor but are not EFP are very different in terms of income (considerably higher) and are less likely to be prepayment customers. Those who are not fuel poor by either measure have even higher incomes and are more likely to be credit customers. About three quarters of this low income sample receives other benefits, whether or not they are fuel poor by either criterion. Retired households are underrepresented in the sample (because fewer retired households have prepayment meters) but those who are 
included are more likely to feel fuel poor, but not to be expenditure fuel poor, than the sample as a whole.

We used a logit regression to examine the determinants of fuel poverty, both FFP and EFP, in more detail from the low income survey data. Income (and therefore EFP) is measured crudely in this data set because income is known only within seven bands. The parsimonious results are presented in table 4. The likelihood of feeling fuel poor and of expenditure fuel poverty are both reduced by higher income, and increased by being on income support. The former has a stronger effect on EFP and the latter on FFP. Those using prepayment and standard electricity tariffs are more likely to feel fuel poor, but gas prepayment reduces the probability of spending more than $10 \%$ of income on energy, showing that the lower consumption levels for such consumers dominate the effect of the higher prices which they pay. Family structure affects EFP, raising its probability for some large households. If the head is unemployed, or all the occupants are retired, a household is less likely to be in expenditure fuel poverty, given other factors in the regression. This is an artefact of the sample chosen, rather than an effect which is likely to be reproduced for the population as a whole. None of the factors identified through data mining (self-disconnection, heating provision or switching) had a significant effect on either measure of fuel poverty, so they are omitted from the parsimonious specification. 
Table 4: Marginal effects of household characteristics on Fuel Poverty: Parsimonious Models; Low income survey

Characteristics

\begin{tabular}{|c|c|c|c|c|}
\hline & Feeling Fue & oor & Expenditure & uel Poverty \\
\hline Income(log) & $\begin{array}{l}\operatorname{Mrg} F x(\%) \\
-6.57^{\star \star \star}\end{array}$ & $\begin{array}{l}\text { Mrg Fx Std } \\
\text { Err } \\
(1.00)+t \dagger\end{array}$ & $\begin{array}{l}\operatorname{Mrg} F x(\%) \\
-32.6^{\star \star \star}\end{array}$ & $\begin{array}{l}\text { Mrg Fx Sto } \\
\text { Err } \\
(1.72)+t+\end{array}$ \\
\hline Gas Paymt Method: & & & $-0<.0$ & \\
\hline Prepayment & & & $-12.81^{\star \star \star}$ & (1.82) ††† \\
\hline $\begin{array}{l}\text { DSS } \\
\text { Standard }\end{array}$ & & & & \\
\hline Elec. Paymt Method: & & & & \\
\hline Prepayment & $15.38^{\star \star \star}$ & (2.9)††† & & \\
\hline $\begin{array}{l}\text { Standard } \\
\text { State Benefits }\end{array}$ & $18.47^{\star \star \star}$ & (6.39)††† & & \\
\hline $\begin{array}{l}\text { Income Support } \\
\text { Household }\end{array}$ & $4.39^{* * *}$ & $(0.01) \dagger \dagger \dagger$ & $2.81^{*}$ & $(1.54) \dagger$ \\
\hline $\begin{array}{l}\text { Composition. } \\
1 \text { Adult! } 2 \text { Chldrn } \\
1 \text { Adult } \geq 3 \text { Chldrn } \\
2 \text { Adults }\end{array}$ & & & & \\
\hline $\begin{array}{l}2 \text { Adults.,2Chldn } \\
2 \text { Adults } \geq 3 \text { Chldn }\end{array}$ & & & $4.11^{*}$ & $(2.32) \dagger$ \\
\hline 3 Adults & & & $9.61^{*}$ & $(5.62) \dagger$ \\
\hline 3 Adults $\geq 1$ Child & & & & \\
\hline Household type & & & & \\
\hline HoH Unemployed & & & $-4.53^{* *}$ & (1.66) ††† \\
\hline Retired & & & $-3.97^{\star \star \star}$ & (1.38) ††† \\
\hline Chi-squared [df] & $143[4]$ & & 1384 [7] & \\
\hline LRI & -1063 & & -825 & \\
\hline$N$ & 2578 & & 5170 & \\
\hline
\end{tabular}

\subsection{Analysis of Family Expenditure Survey}

To explore these factors in a more representative sample, we conducted a similar analysis on the Family Expenditure Survey for the corresponding period, 2000-01.

The results of the logit regression for the FES data are shown in table 5, alongside those of a similar analysis on 1997-98 data from Bennett et al., 2002. Here we see again the significance of income in reducing the probability of EFP and of income support in increasing it. For this larger representative sample the 
effect of family structure is clear, with larger families more likely to be in fuel poverty, other things being equal. In 1997-98 households whose head was retired were at higher risk of fuel poverty, though there is no evidence that this persisted in 2000-01 when other factors are taken into account. In both years standard payment for both gas and electricity lowers the chance of being in fuel poverty compared with paying by direct debit, but in 2000-01 prepayment increases the probability of being EFP. In this case the premium which was then charged for prepayment (around 9\%) dominates the 'rationing' effect from lower consumption. This explanation is credible since the additional charge for prepayment, compared with direct debit (our reference group), increased between 97-98 and 00-01.

While the direction of influence is similar between the two years there are some interesting differences in the size of the marginal effects. The effect of income and of income support are reduced by a small but significant amount, while the effect of payment method has increased. 
Table 5: Marginal effects of household characteristics on 'Expenditure' Fuel Poverty: Parsimonious Model; Family Expenditure Survey

Characteristics

\begin{tabular}{|c|c|c|c|c|}
\hline & $2000-2001$ & & 1997-199 & \\
\hline & Mrg Fx (\%) & Mrg Fx Std Err & Mrg Fx & Mrg Fx Std Err \\
\hline Income(log) & $-7.19^{\star \star \star}$ & $(0.50) \dagger \dagger \dagger$ & $-9.05^{\star \star *}$ & (0.70) ††† \\
\hline \multicolumn{5}{|l|}{ Gas Paymt Method: } \\
\hline \multicolumn{5}{|l|}{ Prepayment } \\
\hline Standard & $-2.04^{\star \star \star}$ & (0.28)††† & $-1.04^{\star \star \star}$ & $(0.37) \mathrm{t \dagger}$ \\
\hline \multicolumn{5}{|c|}{ Elec. Paymt Method: } \\
\hline Prepayment & $0.98^{* *}$ & $(0.47) \dagger \dagger$ & & \\
\hline Standard & $-1.46^{* \star *}$ & $(0.37) \dagger \dagger \dagger$ & $-0.90^{\star * *}$ & $(0.38) \dagger \dagger$ \\
\hline \multicolumn{5}{|l|}{ State Benefits } \\
\hline Income Support & $0.01^{* \star *}$ & $(0.004) \dagger \dagger \dagger$ & $0.64^{* *}$ & $(0.34) \dagger$ \\
\hline \multicolumn{5}{|l|}{$\begin{array}{l}\text { Household } \\
\text { Composition. }\end{array}$} \\
\hline 1 Adult!!2Chldrn & $2.02^{* \star *}$ & $(0.89) \dagger \dagger$ & $2.05^{\star \star}$ & $(0.62) \dagger \dagger$ \\
\hline 1 Adult $\geq 3$ Chldrn & $3.42^{\star \star}$ & $(2.21) \dagger$ & $3.83^{\star \star \star}$ & (0.67) ††† \\
\hline 2 Adults & $0.89^{* *}$ & (0.39) †† & $1.97^{\star \star \star}$ & $(0.42) \dagger \dagger \dagger$ \\
\hline 2 Adults.!2Chldn & $2.70^{\star \star \star}$ & (0.89) ††† & $2.30^{\star \star \star}$ & (0.61) ††† \\
\hline 2 Adults $\geq 3$ Chldn & $5.69^{* \star *}$ & (2.52) ††† & $4.63^{\star \star \star}$ & (0.92) ††† \\
\hline 3 Adults & $8.82^{* * *}$ & (2.69) ††† & $3.83^{* \star \star}$ & (0.92) ††† \\
\hline 3 Adults $\geq 1$ Child & & & $4.66^{\star \star \star}$ & (1.06) ††† \\
\hline \multicolumn{5}{|l|}{ Household type } \\
\hline \multicolumn{5}{|l|}{ HoH Unemployed } \\
\hline Retired & & & $0.78^{\star *}$ & $(0.35) \dagger \dagger$ \\
\hline Chi-squared [df] & $1692[11]$ & & $1748[12]$ & \\
\hline LRI & 0.40 & & 0.44 & \\
\hline $\bar{N}$ & 6299 & & 5170 & \\
\hline
\end{tabular}

\subsection{Robustness}

Several factors may produce inaccuracy in the data or in the estimations. One is the respondent's recollection of energy expenditure. We compared the figures for energy consumption by payment method between the low income survey and the FES. The results are shown in table 6.

\footnotetext{
${ }^{4}$ Source: Bennett et al., 2002
} 
Table 6: Comparison of Annual fuel consumption by payment method, 2000-2001

Prepayment Direct Debit Standard Credit

Gas Electricity Gas Electricity Gas Electricity

Low Income Data (2578 observations)

$\begin{array}{lllllll}\text { Mean } & 416 & 415 & 407 & 322 & 356 & 369 \\ \text { sd } & 194 & 201 & 328 & 167 & 290 & 331 \\ \text { FES Data } & \text { (6299 observations) } & & & & \\ \text { Mean } & 298 & 348 & 361 & 345 & 308 & 319 \\ \text { sd } & 260 & 294 & 201 & 204 & 257 & 498\end{array}$

The FES data show a familiar pattern, with similar levels of expenditure for electricity across the payment methods, but with gas prepayment meter users spending less than standard credit payers, and direct debit users spending most money on fuel. Since the relative prices are in the opposite direction, this implies an even stronger inequality for consumption. However, the low income data, while in the same 'ballpark' as the FES figures, show a rather different pattern. Since the low income sample was designed to be representative of electricity prepayment consumers (as shown in Cooke et al., 2001 table 1.8 and appendix 3 of this document) we would expect a match with the FES figures for these consumers, and by extension for gas prepayment (since they are effectively a lower income subset of electricity prepayers). However, we see that the average consumption figures for prepayment consumers are significantly higher for the low income sample than in the FES. In other categories we would expect the FES figures to be higher because the average income of the respondents is higher (see appendix 3). However, the Low Income Sample shows higher consumption for each category except direct debit electricity. This raises some questions about the accuracy of the self-reported expenditure figures in the household expenditure estimates in the Low Income Survey. We were able to check household estimates against company records for some of the respondents, though we were not able to match sufficient company records to conduct the analysis using these instead of the consumer estimates. This comparison confirmed that consumers did indeed overestimate their own expenditure compared with company records. We also found strong 'mean reversion', i.e. low consumption households overestimated their expenditure, and those who 
consumed large amounts of energy tended to underestimate (Mathieu and Waddams Price, 2004). The net effect of these factors is reinforcing for low consumption consumers (they are likely to have overestimated their expenditure on both counts), but countervailing for high expenditure households (on average the group has overestimated consumption, but consumers of large quantities have underestimated relative to the group). It is this high consumption group, for whom the biases work in opposite directions, who are likely to be EFP. Moreover the focus of this paper is on the feelings of fuel poverty and the implications these have for policy. In this context the consumption estimates, though not exact, provide useful indications of fuel poverty amongst this low income sample and confirm the considerable differences between feeling fuel poor and being fuel poor by the official measure. There is no evidence that the difference between consumer and company estimates is related to income or social grade.

Over a fifth of the households interviewed are excluded from our analysis because they did not answer the income question. While incomes are generally understated in such surveys, item non-response to such questions does not necessarily provide a consistent bias (Lynn et al., 2005). Using the mid-point from the banded income responses may bias income estimates upward, if they are bunched toward the bottom of each band.

\section{Discussion and Conclusions}

The use of our survey data of low income households enables us to explore whether people feel able to afford sufficient energy, and to relate this to the more conventional measure of spending as a proportion of their income. The subjective measure of feeling fuel poor defined in this paper gives very different results from the objective ' $10 \%$ rule' for expenditure fuel poverty. Many households who spend more than $10 \%$ of their income on energy do not feel fuel poor, and not everyone who feels fuel poor spends more than $10 \%$ of their income on fuel. One possible interpretation is that the 231 respondents who feel 
fuel poor but do not spend a tenth of their income on energy are precisely the group who need to do so for adequate provision but do not do so, i.e. their feeling that they cannot afford enough for adequate heat and cooking is because their circumstances lead them to ration spending below $10 \%$ of income. But if this were the case we would expect the characteristics of the FFP to be similar to those of the EFP, whose spending exceeds $10 \%$. Instead we find that the two groups are very different in terms of income and energy expenditure, though similar in many other characteristics. The FFP have substantially higher incomes than the EFP (though lower than the average for this low income sample), though other potential measures of deprivation are broadly similar. The EFP are more likely to use prepayment meters than the FFP, perhaps reflecting the influence of the higher prices charged for prepayment (on average around $9 \%$ higher than direct debit at that time) on fuel poverty. Both fuel poor groups are more likely to use prepayment than the sample as a whole.

The sixth of the sample who feel fuel poor by our definition are therefore more diverse in terms of income and price than the quarter who are EFP (the two factors which affect EFP most dramatically in the short term), but very similar in terms of other potential measures of deprivation. However, among the 700 or so households who spend more than $10 \%$ of their income on energy, the 182 households who also feel fuel poor are very similar in income and other characteristics to the larger group. The differences in the characteristics of the two fuel poor groups are therefore attributable mainly to those who feel unable to afford sufficient energy, but do not spend more than $10 \%$ of their income on energy. Since these households spend less on energy than the EFP do, feeling fuel poor seems to be a phenomenon which is much less directly related to income and fuel expenditure than is expenditure fuel poverty. This is reflected in the logit analysis which identifies payment method (at higher prices) as an important factor in increasing FFP but not EFP, where income is a stronger influence than for FFP. The implication is that if the government focuses on 
increasing income rather than reducing expenditure to meet its EFP targets, it may move people out of EFP but impinge little on how many feel fuel poor.

The data mining method identified aspects associated with each measure of fuel poverty which might not have been anticipated in an ex ante modelling paradigm of social science, and in this way our study provides an element of 'grounded research' in an area where this is an unusual approach. However while these seemed significant when identified individually they did not yield statistically significant results in the logit regressions for either measure of fuel poverty. In particular it is interesting to note that when other factors are included in the analysis, self-disconnection, central heating provision and switching supplier do not affect either objective or subjective measures of fuel poverty. Since the data mining technique found ex ante associations with these factors, this confirms that they are associated with other characteristics which help to explain whether households are fuel poor. For example, those who switch supplier are more likely for other reasons not to be fuel poor. This suggests that policy directed at reducing fuel poverty should be directed at the factors which determine selfdisconnection, heating provision and activity in markets, rather than necessarily directly at these associated elements.

The major factors explaining fuel poverty by both definitions within the low income survey sample and in the Family Expenditure Survey are income level and being in receipt of income support. While retirement was a significant factor in increasing the probability of EFP in 1997-98, this factor is not influential from 2000-01 FES data. In the low income survey, retirement and unemployment seem to reduce the likelihood of fuel poverty, once other factors are taken into account, though we note that there are very few retired households in the low income sample ( $4 \%$ compared with $26 \%$ in the FES). There is evidence that when other factors are held constant, family size affects measures of EFP. Income has not been equivalised (so that the effect of family structure can be observed more directly), and it is interesting that the size of the family (which is 
known to affect heating expenditure as illustrated in the EFP results) does not affect whether or not people feel they can afford enough fuel.

Our results demonstrate that feeling fuel poor is associated with spending more than $10 \%$ of income on energy in the home, but in a complex way. They are positively correlated, and an increase in income would generally reduce both measures. While the data used in this paper reflect feelings and expenditure in 2000, the implications are directly relevant to current policy. Many people who will not be targeted through the Government's drive to eliminate (expenditure) fuel poverty will remain feeling unable to afford adequate heating. Such subjective feelings are not subject to the same influences as EFP, and could have an important effect on policies both for alleviating poverty and for reducing carbon emissions. The Government might wish to develop and monitor ${ }^{5}$ such a subjective measure to inform its energy policy and manage the difficult interaction between environmental and social policy.

\footnotetext{
${ }^{5}$ We are grateful to an anonymous referee for this suggestion.
} 


\section{References}

Bennett, M., Cooke, D. and Waddams Price, C. (2002), "Left Out in the Cold? The Impact of New Energy Tariffs on the Fuel Poor and Low Income Households", Fiscal Studies, 23(2): 167-194.

Blanchflower, D.G. and Oswald, A.J. (2004), "Well-Being Over Time in Britain and the USA", Journal of Public Economics, 88: 1359-1386.

Brazier, J. K., Wang, W., Richards, G. and Waddams, C, "A Data Mining Approach to Understanding UK Fuel Poverty". Proceeding (468) Power and Energy Systems - 2005

Cooke, D., Ferrari, A., Giulietti, M., Sharratt, D. and Waddams Price, C. (2001), Affording Gas and Electricity: Self Disconnection and Rationing by Prepayment and Low Income Credit Consumers and Company Attitudes to Social Action, Electricity Association, March, available from: Centre for Competition Policy, at http://www.ccp.uea.ac.uk/publications.asp\#2001 (accessed 10 November 2005).

DTI Energy Group (2001), The UK Fuel Poverty Strategy, available at: http://www.dti.gov.uk/energy/consumers/fuel poverty/fuel strategy.shtml (accessed 02 December 2005).

DTI Energy Group (2003), The UK Fuel Poverty Strategy - 1st Annual Progress Report, available at: http://www.dti.gov.uk/energy/consumers/fuel poverty/strategy2.pdf (accessed 10 November 2005).

DTI Energy Group (2005), The UK Fuel Poverty Strategy - 3rd Annual Progress Report, available at: http://www.dti.gov.uk/energy/consumers/fuel poverty/strategy third progress re port.pdf (accessed 02 December 2005).

Fuel Poverty Advisory Group (2007), $5^{\text {th }}$ Annual Report, available at: http://www.dti.gov.uk/energy/consumers/fuel poverty/fuel adv grp/report3.pdf

Hancock, R., Pudney, S. and Sutherland, H. (2003), "Using Econometric Models of Benefit Take-up by British Pensioners in Microsimulation Models", Discussion Paper, University of Leicester.

Lynn, P., Buck, N., Burton, J., Jäckle, A. and Laurei, H. (2005), a Review of Methodological Research Pertinent fo Longitudinal Survey Design and Data collection, Institute for Social and Economic Research Working Papers, Number 2005-29 
Mathieu, L and Waddams Price, C (2004), Energy Expenditure of Low Income Consumers: Evidence from Consumers and Suppliers, mimeo

Ofgem (2003) Domestic gas and electricity supply competition. Recent developments, June

Ofgem (2005), Better Targeting Needed to Help Combat Fuel Poverty, available at http://www.ofgem.gov.uk/temp/ofgem/cache/cmsattach/12601_41.pdf (accessed 12 December 2005).

Quinlan, J.R. (1986), "Induction of Decision Trees", Machine Learning 1: 81-106.

Quinlan, J.R. (1993), C4.5: Programs for Machine Learning, San Mateo, CA, Morgan Kaufmann.

Richards, G., Brazier, K.J. and Wang, W. (2005a), A Fast Wrapper Method for Feature Subset Selection, Proceedings of IASTED Conference on AI.

Richards, G., Brazier, K.J. and Wang, W. (2005b), "Feature Salience Definition and Estimation and its Use in Feature Subset Selection", Intelligent Data Analysis, 10, 1, 3-21, 2006

Sefton, T. (2002), "Targeting Fuel Poverty in England: Is the Government Getting Warm?”, Fiscal Studies, 23(3): 369-399.

Waddams Price, C. and Biermann A. (1998), Fuel Poverty in Britain, Expenditure on Fuels 1993-94 to 1995-96, published by the Gas Consumers Council, November.

Wang, W., Jones, P. and Partridge, D. (2001), "A Comparative Study of FeatureSalience Ranking Techniques”, Neural Computation, 13(7): 1603-1623.

Wang, W. (2002), Quantifying Relevance of Input Features, in proceedings of International Conference on Intelligent Data Engineering and Automated Learning (IDEAL02), pp588-593, Manchester, August. 


\section{Appendix 1: Calculation of annual gas and electricity expenditure}

\section{Electricity expenditure}

- Prepayment

Respondents using prepayment as a payment method for electricity were asked to state the average amount of money they had spent on electricity in the summer and in the winter, and whether it was per week, month or quarter. These expenditure values were then converted into monthly payment of electricity in summer (and winter) months.

If respondents gave an average expenditure per week, then amount was multiplied by four; if respondents gave an average expenditure per quarter, then the amount was divided by three.

Total monthly expenditure for prepayment users was obtained by adding 'monthly payment of electricity in summer months' and 'monthly payment of electricity in winter months', then by dividing the sum by two.

- Monthly Direct debit

Respondents using monthly direct debit as a payment method for electricity were asked how much they paid each month.

- Standard credit

Respondents who received electricity bills were asked to state the amount of their last bill and the period it covered (three months, two months, one month, other). These expenditure values were then converted into monthly payment of electricity.

- Annual electricity expenditure

Annual electricity expenditure for each payment method was obtained by multiplying 'monthly electricity expenditure for all payment methods' by twelve.

\section{Gas expenditure}

The questions asked to respondents on gas expenditure were similar to those asked on electricity expenditure and the annual gas bill for all payment methods was calculated in the same way as for electricity. 


\section{Appendix 2: Summary of data mining methodology used for feul poverty data analysis}

Techniques from the data mining field offer alternative methods for analysing data and inducing models from data. They usually do not need to define any hypothesis before analysis, but mine through the given real data to unearth what the data actually represent for and to extract knowledge (relationships, patterns, classes, clusters, and/or association rules etc) from the data. In this study, apart from using some conventional statistical methods such as descriptive analysis, correlation and logit regression analyses to achieve basic understanding of the fuel poverty data, we employed two types of data mining techniques: (1) feature salience estimation and subset selection methods for quantitatively estimating the degree of impact of a factor (variable) on a chosen response variable and then selecting a subset of salient factors for further analysis and modelling, and (2) the methods for generating models automatically with the selected factors for identifying the statues of households in terms of fuel poverty or not for each of the two measures defined in the early sections.

The method chosen for this study was decision tree induction for four reasons. First and most important, it generates a tree-structured diagram model with nodes representing the split threshold of a factor and leaves representing a classification decision. A decision tree model, unlike artificial neural networks which some people consider as a "black box", is transparent and simple, and can be easily interpreted and understood by people in different disciplines; thus it has been wildly used in many different domains for a variety of applications. Second, it can handle mixed variable characteristics, e.g. categorical, ordinal, and nominal, as well as continuous. ${ }^{6}$ Third, it is relatively easy, quick and cheap (in terms of computational cost) to generate many decision tree models, test their performance, and apply them to real world problems. And finally, our feature

\footnotetext{
${ }^{6}$ Though decision tree induction is less efficient, this is not a big concern in our data.
} 
salience estimation method was also developed based on decision tree path analysis.

Many algorithms exist for induction of decision trees. In this study, we chose the algorithm C5.0 (Quinlan 1986, 1993). Broadly speaking, the key idea behind it is based on the information (or Shannon) theory which measures the information quantity (entropy) represented by a feature and finds the best threshold to separate the data into classes.

Feature salience estimation was achieved by the decision tree path analysis method (Wang et al. 2001; Wang, 2002; Richards et al., 2005a, 2005b). This estimates the magnitude of the impact of factors according to the information gains along the decision tree branches to which they contribute, and the proportion of observations classified at the "leaves" at the ends of those branches. Only factors of high estimated salience were selected for further study. With the factors placed in rank order according to their salience estimates, a sharp drop in value was noted for each of the fuel poverty measures. The location of this drop and its level of salience were used to define a cut-off point; factors of lower rank than this were disregarded in the next stage of the analysis.

Salience estimation gives a good indication of the scale of factors' impacts on the response classification, but no indication of their direction of association. Here we have a simple dichotomous outcome class taking values fuel poor or not fuel poor. Thus it is reasonable to talk of a positive (increases likelihood of fuel poor) or negative (increases likelihood of not fuel poor) impact on the response class. To investigate this, multiple logistic regression was used. The directions obtained from this linear (in terms of the log odds ratio) technique were then applied to the salience estimated by the non-linear tree path analysis. Thus estimated sizes of the influence of factors, which reflect the true non-linear nature of the problem, are supplemented with direction of influence information obtainable from the (log transformed) linear approximation. Significance figures for the logistic coefficients 
associated with the factors were also obtained from a Wald test (coefficient divided by its standard error - approximately chi-square distributed). These were used to filter further the factors, applying a threshold of $1 \%$ probability of the null hypothesis (that a factor had no influence). While this mixture of data mining and traditional social science methods limited the availability of the usual tests for robustness of the estimation results, it had the advantage of illuminating the issues and identifying relevant factors.

The fuel poverty data were pre-processed with usual appropriate techniques for dealing with issues such as missing values, outliers, scaling and normalisation. It should be noted that, in this study, we did not attempt to fill the missing values through estimate or other methods, except for the cases where the missing values were obviously of default answers/values (either yes or no), simply for the purpose of like-to-like comparison with some traditional methods used in the social science community. The processed data were then partitioned at random into two subsets, one for model induction (training) and another for evaluation (testing). This training and testing exercise was repeated 10 times and each time the data was reshuffled and repartitioned at random, in order to avoid the biasunbalanced representation between the training and testing data subsets, which may lead to the generation of biased models. The average and standard deviation of the results of 10 runs were calculated and used for comparison with other classification methods, such as logit regression. 
Appendix 3: Income brackets of households using each payment method in Low Income Survey (from Bennett et al., 2002)
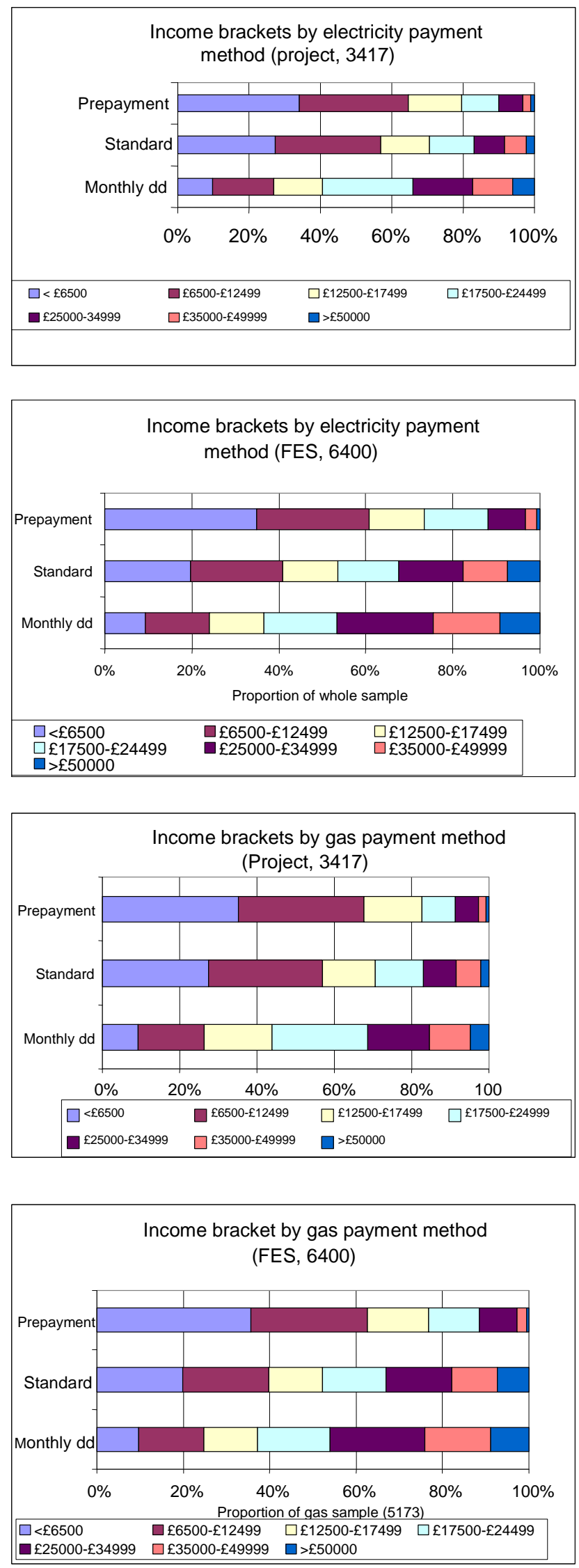